\title{
Measuring Teachers' Perceptions to Sustain STEM Education Development
}

\author{
NGUYEN Thi To Khuyen ${ }^{1}$, NGUYEN Van Bien ${ }^{2}{ }^{-}$, Pei-Ling Lin ${ }^{3}$, Jing Lin ${ }^{4, *}$ and \\ Chun-Yen Chang $3, *$ (D) \\ 1 Graduate Institute of Science Education, National Taiwan Normal University, Taipei 11677, Taiwan; \\ ntkhuyen.aliza.231@gmail.com \\ 2 Faculty of Physics, Hanoi National University of Education, Hanoi 10000, Vietnam; biennv@hnue.edu.vn \\ 3 Science Education Center, National Taiwan Normal University, Taipei 11677, Taiwan; \\ peilinglin0124@gmail.com \\ 4 Collaborative Innovation Center of Assessment for Basic Education Quality, Beijing Normal University, \\ Beijing 100875, China \\ * Correspondence: linjing@bnu.edu.cn (J.L.); changcy@ntnu.edu.tw (C.-Y.C.); \\ Tel: +86-138-1030-6771 (J.L.); +886-2-7734-6751 (C.Y.-C.)
}

Received: 2 January 2020; Accepted: 16 February 2020; Published: 18 February 2020

\begin{abstract}
The 2030 Agenda for Sustainable Development emphasized teachers as the cornerstone for the betterment of education. Teachers' practices are strongly affected by teachers' perceptions. The purpose of this study was to identify teachers' perceptions to sustain STEM education development, regarding STEM education, STEM competencies, and difficulties in STEM implementation. We collected the data from 186 Vietnamese teachers, including STEM sub-field teachers and no STEM sub-field teachers. We used a survey method to capture teachers' perceptions of STEM education. The one-way ANOVA was employed to examine the differences in teachers' perceptions of STEM education in terms of the categorization of teaching experience, education background, and teaching subjects. The quantitative analysis showed that most Vietnamese teachers had positive views on STEM education. The higher educational background teachers and science teachers have the highest statistically significant scores in (1) STEM education, (2) STEM competencies, and (3) difficulties in implementation. The novice teachers have more positive views of STEM education, in terms of a better understanding of STEM education and assessing STEM competencies as being more valuable. There are no statistically significant differences in teachers' difficulties among teaching experience groups. These results provide valuable information to design effective teacher professional development to sustain STEM education.
\end{abstract}

Keywords: teacher education; teacher difficulties; education for sustainable development; STEM education

\section{Introduction}

Vietnamese students are well-known as the top performers in the science test of the Programme for International Student Assessment (PISA). According to the 2015 PISA results reported by the Organization for Economic Co-operation and Development (OECD), Vietnamese students' science performance was ranked 8th among 72 countries [1]. However, Vietnamese students have a low willingness to pursue science, engineer, and technology careers [1] (p. 67). While globalization process demands human resources in science, technology, engineering, and mathematics (STEM) fields [2], how to enhance students' enjoyment to devote science-related careers is an essential issue for Vietnam's sustainable development goals in education. 
Education is crucial in directing the vision for prosperous and sustainable development [3] (p. 27). The 70th General Assembly of the United Nations adopted the 17 Sustainable Development Goals (SDGs), which are known as the Global Goals or the 2030 Agenda for Sustainable Development. The fourth SDG illustrates the most ambitious agenda for global education ever attempted [3] (p. 27). One of the 10 targets is ensuring that all learners acquire knowledge and skills to promote sustainable development [4]. STEM education inherently becomes a promising place for the realization of the ambitious agenda of SDG 4. STEM education enhances not only students' learning achievement [5-7] but also authentic problem-solving skills [8,9]. Besides, STEM education fosters individuals in enjoyments in STEM sub-subjects and pursuance in STEM careers [10-13]. STEM education thereby reflects parts of such a target.

STEM education inherently was deployed to reinforce students' achievement as well as leverage students' pursuance in science-related careers for global goals in Vietnam. On 3 September 2015, the Vietnam Ministry of Education and Training had Official Letter No. 4509/BGDDT-GDTrH to issue a guideline for the implementation of integrated STEM education. Vietnamese teachers and educatorshave deployed STEM education with a variety of STEM activities, such as STEM shows, robotics mini-contests, science camps, STEM clubs, etc. [14].

Teachers are mentioned as critical elements to assure the essential structure in the SDG 4 targets [3] (p. 29). Teachers play important roles in implementing STEM education successfully [15]. However, teaching practices are strongly affected by teachers' perceptions [15-17]. Thus, measuring teachers' perceptions of STEM education is evitable to sustain STEM deployment. Teachers having positive views in STEM education are advocated as the potential teachers to implement STEM education. For example, researchers [16] indicated that experienced teachers have more positive opinions than novice teachers in STEM education or mathematics teachers have less positive views in STEM teaching [17]. Based on teachers' perceptions of STEM education, teachers' difficulties thereby are investigated. Mathematics teachers feel it is more challenging than science teachers in STEM teaching to help students to solve authentic problems [15]. Researchers [18] analyzed teachers' difficulties in teachers' perceptions of STEM education, including pedagogical and curriculum challenges.

Investigation of the philosophy of STEM from national views is essential so that countries have sustainable development of STEM education in society [19]. Three philosophical domains of STEM education encompass ontology, axiology, and epistemology. The three aspects are results for the three questions respectively: What subjects are we studying? Why are we learning STEM? How can we learn STEM? [20]. Of course, revealing teachers' perceptions of STEM education becomes essential when Vietnam is on the way to building Vietnam' s own philosophy. Moreover, research literature describes that teachers' perceptions explained by demographic data have been inconsistent among previous studies. For example, researchers [16] indicated that teachers categorized by teaching years perceived STEM education differently, yet other researchers identified that both novice teachers and experienced teachers had the same perceptions of STEM education [21]. Therefore, we categorize teachers based on their teaching experiences or education backgrounds or teaching subject or STEM education experiences and examine whether there is any difference from subsamples' perceptions of STEM education.

In this study, we will address the questions below:

(1) What are teachers' perceptions of STEM education?

(2) Is there any difference in teachers' perceptions between teaching experience groups?

(3) Is there any difference in teachers' perceptions of educational background groups?

(4) Is there any difference in teachers' perceptions between teaching subject groups?

\subsection{The STEM Education Sustainable Development Goal}

The terms "sustainable" or "sustainability" frequently portray expectations to preserve some readily apparent underlying natural state of equilibrium [22]. Sustainable development, sometimes, 
was simply interpreted as "stained growth," "stained change", or "successful" development [23]. Historically, the phrase sustainable development was popularized since 1987 in the World Commission on Environment and Development WCED report, which entitled Our Common Future ([24], as cited in $[25,26])$. The role of education is spotlighted as directing the vision for prosperous and sustainable development [3] (p. 27). The 70th General Assembly of the United Nations adopted the 17 Sustainable Development Goals (SDGs). The fourth SDG, namely Education for Sustainable Development, with 10 targets illustrating ambitions since the realization of the SDG 4, will transform lives around the globe [3].

Unsurprisingly, since the anxieties of science and society around the word sustainability, sustainability implicitly found its way into education, particularly in the Next Generation Science Standard (NGSS) [25]. While the NGSS is explicitly interdisciplinary within STEM disciplines, integrated STEM education implicitly contained sustainability issues. Social scientific issues (SSIs) are advocated for dynamic contexts to facilitate STEM education [27]. Students were challenged to solve STEM problems that acquire added social argumentations related to the environment, the loss of biodiversity, deforestations, and climate change. Broadly, STEM education inherently involves not only SDG 4 but also some other SDGs related to climate change, for example (SDG 13). The fits within sustainability and STEM education, thereby, are preliminarily sketched.

One often targets SDG 4, ensuring that all learners acquire the knowledge and skills needed to promote sustainable development [4]. The sustainable development of STEM education reflects one part of the target, at least scientific skills, to promote sustainable development [3]. Successful STEM education fosters individuals in learning achievements $[5,7,28,29]$, authentic problem-solving skills [9,30,31], interests in STEM sub-subjects, and in pursuing STEM careers [10-13].

In SDG 4, the targets related to teachers are considered as a means of implication [32-34]. Qualified teachers are spotlighted as the cornerstone for education for sustainable development goals. Similarly, an adequate supply of qualified STEM teachers is evitable to sustain STEM education. Notably, teacher qualifications include both academic and training qualifications [32]. In other words, teachers need to be frequently trained by effective professional developments. While STEM education is advocated as innovation teaching, assessing teachers' perceptions plays a critical role to prepare for effective professional development [35].

\subsection{The Current Status of STEM Education in Vietnam}

STEM education in Vietnam began in 2015. Since then, there have been a variety of STEM activities in Vietnam, but informal activities have been the majority of said endeavors. Initially, while the public schools only cautiously deployed STEM education, gifted schools, private schools, and private educational centers had plenty of STEM activities [14] (p. 40), such as science shows, robotics mini-contests, science camps, STEM clubs, etc. Besides, there are some community activities, such as the National STEM Day, and STEM days in schools or cities. These events involved not only students, teachers, and educators but also parents, universities, and educational companies. Because of the disseminated community effect in the educational community, STEM education is often quickly adopted by teachers as well as school managers.

In Vietnam, the formal teaching of STEM faces many challenges, such as the inflexible current educational curriculum and the lack of STEM materials and STEM labs [14] (p. 42). The Vietnam Ministry of Education and Training conducted the Second Secondary Education Sector Development Program to enhance STEM education in schools [36]. However, there has not been an official STEM curriculum yet. Teachers need to modify the current educational curriculum and arrange a suitable timetable to implement STEM modules [14]. As STEM education is an innovative pedagogy, it uses models, experiments, and simulations. The lack of STEM materials and STEM labs is issued to implement STEM education [14,16]. 


\subsection{Teachers' Perceptions of STEM Education}

Demand for pedagogical innovations has arisen to deploy STEM education successfully. Vietnamese teaching strategies are still didactic, discourages creativity, and subject matter centric [14,36]. Vietnamese teaching habits straggly shift into an integrated approach in STEM education [14] (p. 42). The context led Vietnamese educators to make an effort to innovate teachers' teaching style toward integrated teaching. Teachers' perceptions strongly impacted instructional design and implementation $[15,37,38]$. Therefore, the prerequisite to have efficient pedagogy is an interpretation of teachers' perceptions of STEM education.

There are many studies to interpret teachers' perceptions of STEM education (for example, [15,16,21,39-43]). STEM education is framed into three aspects: STEM education, STEM competencies, and STEM difficulties. Mainly, teachers' perceptions of STEM education are investigated as a variety of components, such as conception, attitudes, beliefs, difficulties, or self-efficacy. Researchers [15] conducted the study to look at teachers' understanding and implementation of STEM integration. Researchers [15] found that (1) problem-solving competence is the core competency in STEM education, and (2) there are different perceptions of alternative teachers' disciplines about STEM integration and that leads to different teaching practices. Accordingly, teachers' challenges were pointed out. In this study, we measured teachers' perceptions of STEM education following three components: (1) STEM education (STEMUnd); (2) STEM competencies (STEMCom); and (3) STEM difficulties (STEMDif).

\subsection{Factors Related to Teachers' Perceptions of STEM Education}

In the standard coding for perception and action, while action approached the event-to-be-affected, perception approach to event-to-be-represented [38]. Even though they have similar knowledge and skills, people have alternative representations [44] that influence and are influenced by personal factors in the form of cognition, affect, and biological events [45]. In this study, personal factors encompass teaching experience, educational background, and teaching subjects.

\subsubsection{Teaching Experience}

The notion of mastery experience occurs when people attempt to execute a specific something successfully. People can accomplish something new that is similar to previous things that they have already done successfully [46]. Mastery experiences can reinforce people's belief in their efficacy capacities, namely self-efficacy $[44,45]$. Theoretically, teachers' perceptions are influenced by how long they have taught because mastery experiences were accumulated by time. Empirically, researchers [47] indicated that novice teachers' scores of the efficacy are unstable during the first teaching year.

Consequently, the teaching year becomes the accessible demographic datum to explain the differences in teachers' perceptions of STEM education. However, the teaching year was an inconstant factor between alternative research. For example, there were differences in teachers' perceptions based on teaching experiences in South Korean [16], but researchers in Thailand [21] indicated no differences. In this current study, mastery experiences are measured by teaching years in the ongoing educational system.

\subsubsection{Educational Background}

Teachers who have different educational levels had dissimilar personal perceptions because of the diversities of differences in instructional models among scholastic levels [48,49]. Perhaps, teachers were possessed by what and how their teachers guided when they were students. In other words, teachers teach based on their vicarious experience when they were students [44]. Teachers who have different academic backgrounds could have distinctive perceptions of STEM education (e.g., most top [43]). 


\subsubsection{Teaching Subjects}

The nature of the teaching subject constructs teaching assignments so teaching experiences in specific STEM domains are a predictive factor for differences in teachers' perceptions of STEM education [50]. For example, researchers [17] found that teachers who have experience in mathematics had a lower attitude toward teaching integrated STEM than other subjects. In our study, teaching subjects are hypothesized as demographic data to categorized teachers. We find differences in teachers' perceptions of STEM education between sub-samples.

Figure 1 illustrates teachers' perceptions of STEM education and factors, which were utilized to categorize for sub-samples.

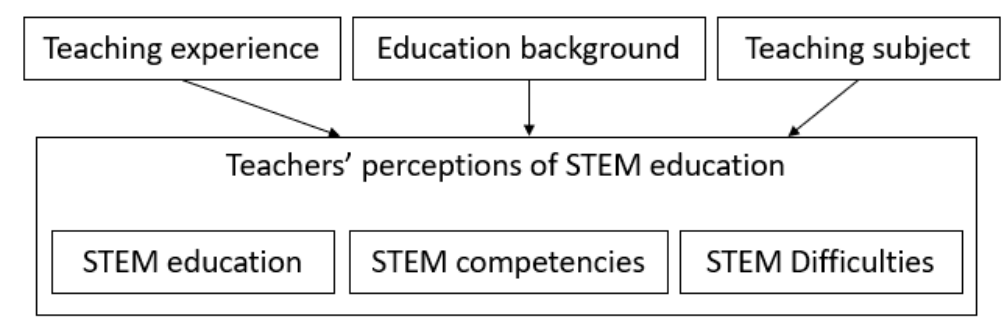

Figure 1. The demographic data for categorizing subsamples.

\section{Materials and Methods}

\subsection{Procedure and Sample}

We utilized survey methodology to measure teachers' perceptions of STEM education in Vietnam. In the current study, the cross-sectional survey has three components, STEMUnd, STEMCom, and STEMDif. The authors surveyed to collect data in five months from July to December in 2018 with both paper and online versions. Paper version surveys were given to teachers to respond to some workshops in Vietnam. Facebook was utilized as a space to conduct online surveys. The quantitative analysis was utilized to address the research questions.

Table 1 illustrated the demographics of respondents. The authors collected data from 186 in-service teachers from both rural areas (51.6\%) and urban areas (48.4\%) in Vietnam. Most participants teach in primary schools, junior high schools, and senior high schools. Only $5.4 \%$ of participants are lecturers in universities. The majority of teachers $(70.4 \%)$ had a bachelor's degree. The minority of teachers $(8.1 \%)$ had a diploma degree, which is below the level of a bachelor's degree in Vietnam. More than half of the teachers have more than 10 years of teaching. Science teachers are the majority $(40.3 \%)$. Fifty-five primary teachers teach multiple subjects, including mathematics, Vietnamese, and science. Besides, $7 \%$ of teachers did not have any teaching subject(s) in a STEM sub-field, such as English, art, and physical education.

\subsection{The Development and Validity of the Instrument}

The current study aimed to interpret how teachers perceive STEM education in (1) STEM education, (2) STEM competence, and (3) STEM difficulties. Teachers' overall perceptions of STEM education (STEMUnd) were based on teachers' responses to four items: (1) The concept of STEM education is teaching about knowledge, skills, and logical thinking related to STEM careers; (2) the STEM lesson does not need to be combined in all four sub-fields; (3) scientific inquiry and engineering design are the two main factors in STEM education; and (4) the term "technology" in STEM is not solely restricted to the means of technological tools in the classroom, such as computers, projectors, and cameras, etc. Teachers responded on a five-point scale from strongly disagree to strongly agree. The average score of four items was utilized to interpret teachers' overall perceptions of STEM education per se. The range of item factor loadings was from 0.56 to 0.77 . Secondly, teachers were asked to respond to a five-point scale of no importance to extreme importance to value STEM competencies (STEMCom), which are (1) 
skills related directly to STEM careers, (2) critical thinking, (3) authentic problem-solving skills, (4) collaboration, and (5) engineering design (defining the needs, designing, and making models). Item factor loadings ranged from 0.80 to 0.85 . Finally, participants responded on a five-point Likert scale of disagreement to agreement for five difficulties in STEM implementation (STEMDif): (1) Finding an idea; (2) enhancing integrated knowledge beyond the major; (3) assessing students' achievement; (4) arrangement of extra time for students; and (5) expense of materials and equipment for a STEM lesson. Item factor loadings ranged from 0.63 to 0.78 . In addition, we analyzed not only the average score of teachers' perceptions of STEM competencies and difficulties but also analyzed each item separately to better examine how teachers value STEM competencies and what challenges teachers face in STEM implementation.

Table 1. The distribution of teachers by education background, teaching experience, and teaching subject(s).

\begin{tabular}{ccc}
\hline Variable & $\mathbf{n}$ & Percentage (\%) \\
\hline Education background & & \\
Diploma & 15 & 8.1 \\
Bachelor & 131 & 70.4 \\
Master and PhD & 40 & 21.5 \\
\hline Teaching Experience & & \\
<5 years & 33 & 17.7 \\
5-10 years & 50 & 26.9 \\
>10 years & 103 & 55.4 \\
\hline Teaching subject & & \\
Science & 75 & 40.3 \\
Technology and Engineering & 15 & 8.1 \\
Mathematics & 28 & 15.1 \\
Non-STEM & 55 & 29.6 \\
\hline
\end{tabular}

The Kaiser-Mayer-Olkin (KMO) and Barlett's test of sphericity were performed to verify the sampling adequacy. The KMO sampling adequacy test score was 0.863 , indicating that the variables were highly factorable [51] (p.676). The Barlett's test of sphericity is statistically significant at the $p<0.001$ level. The results indicate that the variables are correlated. In total, $64.35 \%$ of total variance was accounted for as explained by the three factors identified. We found three components by using principal component and Varimax with the Kaiser normalization rotation method. The three components are STEMUnd (item 1 to 4), STEMCom (item 5 to 9), and STEMDif (item 10 to 14)

We utilized the Cronbach alpha (alpha) to evaluate the reliability as internal consistency. The calculated alphas of STEMUnd, STEMCom, and STEMDif were respectively 0.764, 0.919, and 0.774. Researchers [51] indicated the magnitude of alphas, with values between 0.70 to 0.79 considered reliable, and values greater than 0.90 considered very highly reliable. In the current study, the calculated alphas indicated a reliable and very highly reliable scale. Finally, we had the 14 -item instrument, including three components, namely STEMUnd (4 items), STEMCom (5 items), and STEMDif (5 items).

\subsection{Analytical Strategies}

Descriptive statistic data were utilized to address the first question. The last three research questions were explored by comparing the differences between subsamples. Using one-way ANOVA, the differences in teachers' perceptions in different groups categorized by teaching experience, education background, and teaching subjects were interpreted. Tukey honestly significant difference (HSD) tests were utilized for post hoc comparisons. The eta-squared was calculated to examine the effect size of differences between groups. Researchers [52] classified 0.01 as a small effect, 0.06 as a medium effect, and 0.14 as a large effect. All analyses were completed using SPSS 20. 


\section{Results}

\subsection{Vietnamese Teachers' Perceptions of STEM Education}

The mean of each domain was calculated to interpret the overall teachers' perceptions of STEM education regarding STEM education, STEM competencies, and difficulties in STEM implementation (STEMUnd: $(M=3.75, S D=0.694)$; STEMCom: $M=4.03, S D=0.675$; STEMDif: $M=3.85, S D=0.628$ ). The following boxplots illustrate the distribution of each domain (Figure 2). For STEMUnd, the first quartile (Q1) is about 3.25. One can say that more than $75 \%$ of in-service teachers had reasonable general understandings in STEM education. Q1 of the second domain is about 3.75. That means more than $75 \%$ of in-service teachers think STEM competencies are important. The median of the second domain was about 4.00. In other words, 50\% of participants thought that STEM competencies are important and extremely important. The interquartile range (IQR) of the STEMDif fluctuated around 4.00. Most of the teachers felt it was difficult to implement STEM education. To summarize, Vietnamese teachers had a great reasonable STEM education and assumed STEM competencies to be important. However, they felt it was difficult to implement STEM education.

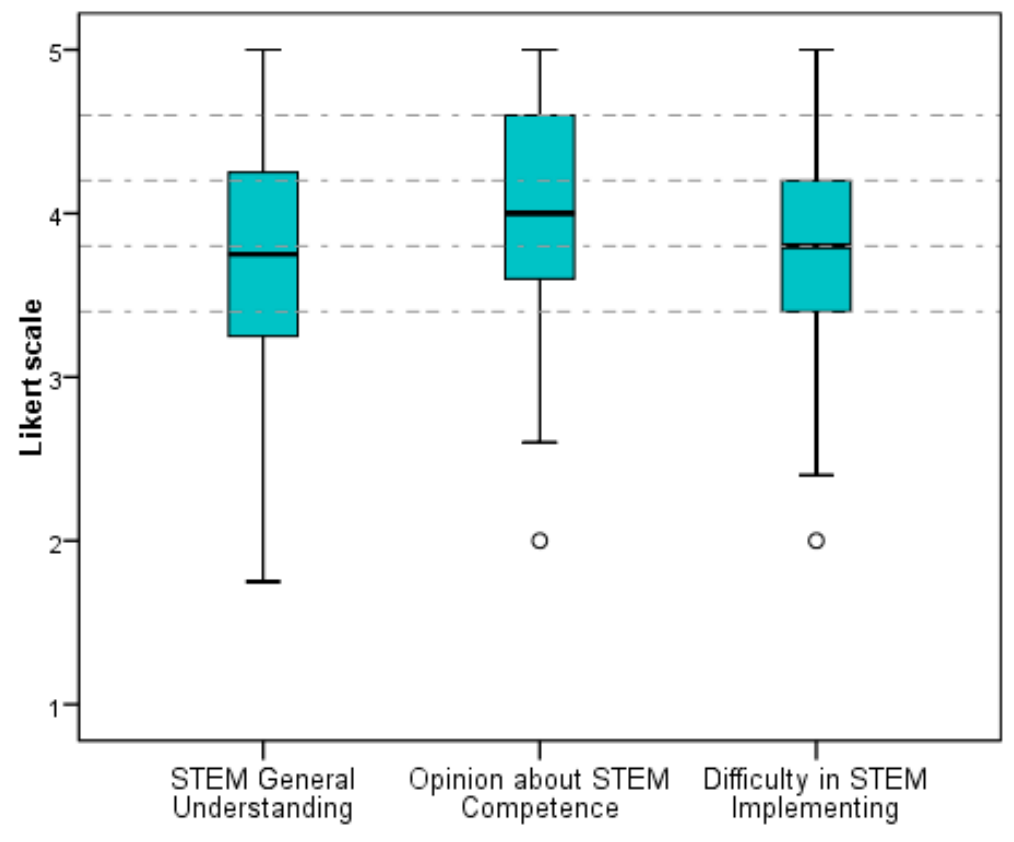

Figure 2. Distribution of each domain in the survey instrument.

There were five STEM competencies and five difficulties that teachers faced when implementing STEM education. Respondents were asked to assess the importance of each STEM competency and the level of difficulty. Table 2 shows the mean, the standard deviation, and the 95\% confident interval (CI) of each item in STEMCom and STEMDif. The authentic problem solving was advocated as the most important STEM competency while skills related directly to STEM careers were advocated as the least important STEM competency. Enhancing knowledge beyond major related STEM subfields and arranging extra time for students to learn were the two main difficulties of implementing STEM education. The expenses of the materials and equipment, which are utilized in STEM lessons, were assessed as the least difficult when comparing with the other four difficulties. 
Table 2. Means, standard deviations, and the 95\% CI for the level of importance of each STEM competency and level of each difficulty in STEM implementation.

\begin{tabular}{|c|c|c|c|c|}
\hline \multirow{2}{*}{ Variable } & \multirow{2}{*}{$M$} & \multirow{2}{*}{$S D$} & \multicolumn{2}{|c|}{$95 \% \mathrm{CI}$} \\
\hline & & & LL & UL \\
\hline \multicolumn{5}{|l|}{ STEMCom } \\
\hline skills which related directly to STEM careers & 3.94 & 0.793 & 3.82 & 4.06 \\
\hline critical thinking & 3.97 & 0.828 & 3.85 & 4.09 \\
\hline authentic problem solving & 4.14 & 0.790 & 4.03 & 4.26 \\
\hline collaboration literacy & 4.08 & 0.734 & 3.98 & 4.19 \\
\hline engineering abilities & 4.02 & 0.735 & 3.91 & 4.13 \\
\hline \multicolumn{5}{|l|}{ STEMDif } \\
\hline finding an idea & 3.91 & 0.843 & 3.78 & 4.03 \\
\hline enhance knowledge beyond the major, related to STEM subfields & 4.05 & 0.804 & 3.94 & 4.17 \\
\hline formative assessment for students' achievement & 3.84 & 0.793 & 3.72 & 3.96 \\
\hline arranging extra time for students to learn & 4.01 & 0.879 & 3.88 & 4.13 \\
\hline the materials and equipment which are utilized STEM lessons are expensive & 3.43 & 0.995 & 3.28 & 3.56 \\
\hline
\end{tabular}

Note: STEMCom = STEM competence. STEMDif = Difficulty when implementing STEM education. CI = confident interval. $\mathrm{LL}=$ lower limit. $\mathrm{UL}=$ upper limit.

\subsection{Differences in Teachers' Perceptions of STEM Education Based on Teaching Experiences}

To examine whether there is any difference from subsamples' perceptions of STEM education, we utilized one-way ANOVAs and post hoc comparisons.

The mean (M) and standard deviation (SD) of each group are illustrated in Table 3. The post hoc comparisons are shown in Table 4.

Table 3. Teachers' perceptions based on teaching experience, education background, teaching subjects, and STEM education experience.

\begin{tabular}{|c|c|c|c|c|c|c|c|c|c|c|c|c|c|}
\hline \multirow{2}{*}{ Variable } & \multirow[t]{2}{*}{$\mathbf{n}$} & \multicolumn{4}{|c|}{ STEM Education } & \multicolumn{4}{|c|}{ STEM Competence } & \multicolumn{4}{|c|}{$\begin{array}{l}\text { Difficulty in STEM } \\
\text { Implementing }\end{array}$} \\
\hline & & $M$ & $S D$ & $p$ & $\eta^{2}$ & $M$ & $S D$ & $p$ & $\eta^{2}$ & $M$ & $S D$ & $p$ & $\eta^{2}$ \\
\hline Teaching Experience & & & & $0.041 *$ & 0.03 & & & 0.002 ** & 0.06 & & & 0.932 & $<0.01$ \\
\hline$<5$ years & 33 & 3.88 & 0.766 & & & 4.39 & 0.589 & & & 3.88 & 0.614 & & \\
\hline $5-10$ years & 50 & 3.89 & 0.623 & & & 4.02 & 0.619 & & & 3.86 & 0.660 & & \\
\hline$>10$ years & 103 & 3.63 & 0.688 & & & 3.92 & 0.693 & & & 3.83 & 0.621 & & \\
\hline Education background & & & & $0.001^{* *}$ & 0.07 & & & $* * *$ & 0.12 & & & $\underset{*}{0.020}$ & 0.04 \\
\hline Diploma & 15 & 3.37 & 0.441 & & & 3.70 & 0.699 & & & 3.45 & 0.819 & & \\
\hline Bachelor & 131 & 3.69 & 0.715 & & & 3.94 & 0.673 & & & 3.85 & 0.614 & & \\
\hline Master and $\mathrm{PhD}$ & 40 & 4.06 & 0.585 & & & 4.45 & 0.472 & & & 3.98 & 0.539 & & \\
\hline Teaching subject(s) & & & & $0.042 *$ & 0.05 & & & $* * *$ & 0.16 & & & $* * *$ & 0.14 \\
\hline Science & 75 & 3.91 & 0.744 & & & 4.32 & 0.567 & & & 4.08 & 0.570 & & \\
\hline Technology and Engineering & 15 & 3.75 & 0.535 & & & 4.07 & 0.598 & & & 3.67 & 0.569 & & \\
\hline Mathematics & 28 & 3.77 & 0.710 & & & 4.02 & 0.621 & & & 4.00 & 0.609 & & \\
\hline Multiple subjects & 55 & 3.56 & 0.581 & & & 3.69 & 0.682 & & & 3.58 & 0.596 & & \\
\hline Non-STEM & 13 & 3.52 & 0.794 & & & 3.77 & 0.706 & & & 3.51 & 0.598 & & \\
\hline
\end{tabular}

Note: Eta squared values $\geq 0.06$ are in boldface. ${ }^{*} p<0.05 .{ }^{* *} p<0.01 .{ }^{* * *} p<0.001$.

Overall, teachers with experience more than 10 years had the lowest score in STEM education, advocated STEM competency as the least important, and felt the least difficulty in STEM education implementation. The one-way between-groups ANOVA was conducted to explore differences in teachers' perception of STEM education based on teaching experiences. There were statistically significant differences at the $p<0.05$ level in STEMUnd scores $(F(2,183)=3.2, p=0.041)$ and in STEMCom scores $(F(2,183)=6.3, p=0.002)$ for all teaching experience groups. However, there were no statistically significant differences at the $p<0.05$ level in STEMDif scores $(F(2,183)=0.1, p=0.932)$. Based on the eta squared, actual differences in mean scores between groups were small and very small in STEMUnd $\left(\eta^{2}=0.03\right)$ and STEMCom $\left(\eta^{2}=0.06\right)$. Meanwhile, actual differences in mean scores between groups were medium in STEMCom $\left(\eta^{2}=0.06\right)$. Next, post hoc comparisons using the Tukey HSD test indicated that there was no statistical significance among the mean scores of three teaching 
experience groups in STEMUnd ( $<5$ years: $M=3.88, S D=0.766 ; 5-10$ years: $M=3.89, S D=0.623$; > 10 years: $M=3.63, S D=0.688$ ) and STEMD if ( $<5$ years: $M=3.88, S D=0.614 ; 5-10$ years: $M=3.86$, $S D=0.660$; $>10$ years: $M=3.83, S D=0.621)$, yet in STEMCom. In STEMCom, the mean scores of teachers having less than five $(M=4.39, S D=0.589)$ years of experience are statistically significantly higher than either those having 5 to $10(M=4.02, S D=0.619)$ teaching years or more than 10 teaching years $(M=3.92, S D=0.693)$.

Table 4. Post hoc comparisons in teachers' perceptions of STEM education.

\begin{tabular}{|c|c|c|c|c|c|c|c|}
\hline \multicolumn{2}{|c|}{ Demographic Category } & \multicolumn{2}{|c|}{ STEMUnd } & \multicolumn{2}{|c|}{ STEMCom } & \multicolumn{2}{|c|}{ STEMDif } \\
\hline (I) & (J) & $\begin{array}{c}\text { Mean } \\
\text { Difference } \\
(\mathrm{I}-\mathrm{J})\end{array}$ & SE & $\begin{array}{c}\text { Mean } \\
\text { Difference } \\
(\mathrm{I}-\mathrm{J})\end{array}$ & SE & $\begin{array}{c}\text { Mean } \\
\text { Difference } \\
(\mathrm{I}-\mathrm{J})\end{array}$ & SE \\
\hline \multicolumn{8}{|c|}{ Teaching Experience } \\
\hline$<5$ years & $5-10$ years & -0.02 & 0.154 & 0.372 & 0.147 & 0.02 & 0.141 \\
\hline$<5$ years & $>10$ years & 0.25 & 0.137 & 0.464 & 0.131 & 0.05 & 0.126 \\
\hline $5-10$ years & $>10$ years & 0.26 & 0.118 & 0.09 & 0.113 & 0.02 & 0.109 \\
\hline \multicolumn{8}{|c|}{ Education background } \\
\hline Diploma & Bachelor & -0.33 & 0.183 & -0.24 & 0.174 & -0.40 & 0.168 \\
\hline Diploma & Master and Ph.D. & -0.70 & 0.203 & -0.75 & 0.193 & -0.53 & 0.187 \\
\hline Bachelor & Master and Ph.D. & -0.37 & 0.121 & -0.51 & 0.115 & -0.13 & 0.112 \\
\hline \multicolumn{8}{|c|}{ Teaching subject(s) } \\
\hline Science & $\begin{array}{l}\text { Technology and } \\
\text { Engineer }\end{array}$ & 0.16 & 0.205 & 0.28 & 0.181 & 0.42 & 0.166 \\
\hline Science & Mathematics & 0.14 & 0.160 & 0.32 & 0.146 & 0.09 & 0.130 \\
\hline Science & Multiple subjects & 0.39 & 0.131 & 0.67 & 0.116 & 0.51 & 0.104 \\
\hline Science & Non-STEM & 0.41 & 0.219 & 0.58 & 0.192 & 0.58 & 0.176 \\
\hline Technology and Engineer & Mathematics & -0.02 & 0.234 & 0.04 & 0.206 & -0.33 & 0.188 \\
\hline Technology and Engineer & Multiple subjects & 0.22 & 0.215 & 0.39 & 0.186 & 0.09 & 0.171 \\
\hline Technology and Engineer & Non-STEM & 0.25 & 0.277 & 0.30 & 0.241 & 0.16 & 0.222 \\
\hline Mathematics & Multiple subjects & 0.24 & 0.172 & 0.35 & 0.152 & 0.42 & 0.136 \\
\hline Mathematics & Non-STEM & 0.27 & 0.246 & 0.25 & 0.216 & 0.49 & 0.197 \\
\hline Multiple subjects & Non-STEM & 0.03 & 0.228 & -0.09 & 0.197 & 0.07 & 0.181 \\
\hline
\end{tabular}

\subsection{Differences in Teachers' Perceptions of STEM Education Based on Education Backgrounds}

Teachers having Master and PhD degrees had the highest mean scores, while teachers having diploma degrees had the lowest mean scores in the three domains. In other words, teachers who have a higher level of education had a more reasonable general understanding in STEM education, advocated STEM competency as more important, but felt more difficulty in STEM education implementation. The one-way between-groups ANOVA was conducted to explore the influence of teachers' education background on the perception of STEM education. There were statistically significant differences at the $p<0.05$ level in STEMUnd scores $(F(2,183)=7.3, p=0.001)$, STEMDif scores $(F(2,183)=4.0$, $p=0.001)$, and $p<0.001$ level in STEMCom scores $(F(2,183)=11.9)$ for three education background groups. Base on the eta squared, actual differences in the mean scores between groups were medium in STEMUnd $\left(\eta^{2}=0.07\right)$ and quite large in STEMCom $\left(\eta^{2}=0.12\right)$. Despite reaching statistical significance, the actual difference in mean scores of STEMDif between groups was quite small $\left(\eta^{2}=0.04\right)$. Post hoc comparisons using the Tukey HSD test indicated that the mean scores for Master and PhD group of STEMUnd $(M=4.06, S D=0.585)$ and STEMCom $(M=4.450, S D=0.472)$ were statistically significantly higher than those of either the diploma group or Bachelor group. The diploma group had mean scores in STEMUnd $(M=3.37, S D=0.441)$ and STEMCom $(M=3.70, S D=0.699)$ that did not differ statistically significantly from the Bachelor group in STEMUnd $(M=3.69, S D=0.715)$ and STEMCom $(M=3.94, S D=0.673)$. Using a similar methodology, we concluded that the mean scores in STEMDif of the diploma group $(M=3.45, S D=0.819)$ were statistically significantly lower than either the Bachelor or Master and PhD group. There was no statistical difference between the mean scores in STEMDif of the Bachelor group $(M=3.85, S D=0.614)$ and Master and PhD group $(M=3.98, S D=0.539)$. 


\subsection{Differences among Teachers' Perceptions of STEM Education Based on Teaching Subjects}

Science teachers had the highest mean scores in all domains. Primary teachers had the lowest mean scores when comparing among STEM sub-fields' teachers. That is, primary teachers had a less reasonable general understanding in STEM education, advocated STEM competency as less important, and felt less difficulty in STEM education implementation than other STEM sub-fields' teachers. One-way ANOVAs indicated statistically significant differences at the $p<0.05$ level of STEMUnd ( $F(4$, $181)=2.5, p=0.042)$ and the $p<0.001$ level of STEMCom $(F(4,181)=8.9)$ and STEMDif $(F(4,181)$ $=7.9$ ) for alternative teaching subject(s) groups. The actual differences of mean scores in STEMUnd between groups was quite medium $\left(\eta^{2}=0.05\right)$ while ones in STEMCom $\left(\eta^{2}=0.16\right)$ and STEMDif $\left(\eta^{2}=\right.$ 0.14) were large. Post hoc comparisons using the Tukey HSD test indicated that only the mean scores of STEMUnd of science teachers $(M=3.91, S D=0.744)$ were statistically significantly higher than the primary teachers $(M=3.56, S D=0.581)$ group. The mean scores of STEMCom of science teachers $(M=$ $4.32, S D=0.567)$ were statistically significantly higher than either primary teachers $(M=3.69, S D=$ $0.682)$ or non-STEM teachers $(M=3.77, S D=0.706)$. There were statistically significant differences in STEMDif between primary teachers and either science teachers or mathematic teachers, and science teachers and non-STEM teachers.

\section{Discussion}

\subsection{Being a STEM Thinker Before a STEM Teacher for the STEM Education Sustainable Development}

Overall, Vietnamese teachers perceived the foci STEM education and value STEM competencies. However, they felt it was difficult to implement STEM education. Integrated STEM education was perceived as the teaching and learning of some STEM subjects or even combines with other school subjects [9]. Teachers could be challenged with both contented knowledge and pedagogy knowledge. Regarding content knowledge, teachers might struggle with other subject matters that they have not known to teach well [53]. It is reasonable that enhancing knowledge beyond teachers' majors was advocated as the most difficult in STEM implementation. About pedagogy knowledge, teachers might be challenged with how to teach integration. Most of the specific method courses in training institutes are taught separately [54] and curricular activities need to be taught alternatively depending on subject features $[55,56]$. Therefore, teachers need to shift their habits of teaching to transfer across STEM sub-subjects' boundaries to approach successful STEM education [57].

The use of social scientific issues (SSIs) has emerged as a promising place for STEM implementation because SSIs enable teachers initially to think about the problems per se rather than discipline matters [27]. This means SSIs can facilitate teachers to transfer across STEM sub-subjects' boundaries. However, teachers have faced challenges to solve authentic problems toward STEM thinking. For example, system thinking of engineering design is the requirement to solve STEM-related issues [58,59]. Students could restructure their thinking process following distinguishable STEM thinking [60]. Therefore, it raises the challenge that teachers need to initially become a STEM thinker first to instruct students' thinking. Professional training for STEM thinking shows promise for qualified teachers to sustain STEM implementations.

\subsection{Reinforcement of Teachers' Awareness of STEM Careers}

Historically, STEM education appeared to prepare the STEM workforce [20]. The sustained STEM implementations inspire students to future STEM careers. Surprisingly, Vietnamese teachers assumed skills related to STEM careers as the least important competency in STEM education's outcomes. This finding is astonishing because the Vietnam government established the scheme related to educating students' future careers, which were highlighted with STEM careers in 2018. The pedagogical teaching impacts on students' career aspirations. Therefore, teacher learning activities need to be set to engage teachers not only in understanding STEM initiatives but also leveraging teachers' awareness of STEM careers [61]. Teachers thereby will recognize STEM education as more valuable regarding fostering 
STEM career skills for students. Sustained STEM education enables students to acquire skills, including scientific skills and career skills. In other words, sustained STEM education contributed to the targets in SDG 4.

\subsection{Differences in Teachers' Perceptions of STEM Education between Subsamples}

There were statistical differences between groups categorized by teaching years, in terms of STEM education and assessing STEM competencies. Yet, there were no statistical differences within teaching experience groups in the difficulties regarding STEM implementation. It is noted that most of the Vietnamese teachers perceived STEM competency as being valuable. However, compared with the veteran teachers, the novice teachers ( $<5$ teaching years) perceived STEM education as more reasonable and perceived STEM competency as more valuable than the rest of the teachers. Our finding, which is the newest teachers perceived STEM education as more valuable, is consistent with the previous study [62]. Researchers pointed out that teachers' experiences and their ratings on the importance of instructional innovations' implementation were related negatively. The more experience teachers accumulated, the less teachers' enthusiasm for adopting new instructional innovations [62]. Novice teachers often had more optimistic and less problematic views than veteran teachers [63]. Novice teachers easily approached and gained educational innovations, such as STEM education. Particularly, because the STEM education environment has been more informal in Vietnam, novice teachers are energetic in participating in informally convened meetings, workshops, and networking in educational centers related to STEM sub-fields, such as science, mathematics, and robotics. In the Vietnam context, novice teachers are advocated as a potential resource to sustain STEM education.

The higher education backgrounds, the more reasonable the general understanding in STEM education, and advocating STEM competency as more important. These findings are reasonable since postgraduate academic brings substantial learning to teachers, particularly in terms of educational innovations. In other words, there are positive gains for those who undertake postgraduate study to have both professional and personal growth [64]. Some teachers realized that they could acquire the ability, which they did not think existed before they got master programs [15]. Our findings demonstrated that the higher educational background teachers had, the more reasonable their general understanding in STEM education. A similar phenomenon occurred with the Indonesian teachers [35]: Teachers who had higher educational backgrounds performed better STEM knowledge. Teachers who had a higher educational background assessed STEM competencies as more valuable. Teachers have chances to be familiar with pedagogic innovations in postgraduate. Interestingly, the highest educational background group feels the most difficulty in STEM implementation. However, teachers' ratings on difficulties in implementation and their willingness to engage in new practice are unrelated [63] if teachers still perceived STEM education as more valuable. To sustain STEM education, supplying qualified teachers in both academic qualifications and training qualifications are evitable [32].

Based on the results, there was a similarity phenomenon between the highest educational background teachers and science teachers. Science teachers had the most reasonable general understanding in STEM education, and assessed STEM competencies as the most important. Science teachers are promising resources for success in STEM implementation in Vietnam. The actual differences of the mean scores in teachers' perception of STEM education between teaching experience groups and education background groups were only small or medium. Meanwhile, the actual differences of mean scores in the STEM competencies and feeling about difficulties in STEM implementation between groups categorized by teaching subjects were large. In the Vietnam context, because most secondary high school teachers have approached STEM sub-subjects separately, they have struggled to approach them beyond their inherent major teaching styles and thinking [14]. This problem was pointed out in the challenge related to workforces for STEM sustained implementation in Vietnam by the previous study [14]. To avoid risks in approaching sustainability, teachers need to seek partnerships for curricular and pedagogical collaboration that combine the needful strengths of both fields [25]. 


\section{Conclusions}

Teachers' perceptions of STEM education, including STEM education, STEM competence, and difficulties when implementing STEM education, were interpreted in this current study. Most Vietnamese participants had positive views on STEM education. This reflects part of the favorability to sustain STEM education in Vietnam. Supplying qualified teachers in both academic and training qualifications is a necessity. Professional development needs to be emphasized in STEM thinking and awareness of STEM careers. This facilitates the realization of STEM education for sustainable development goals.

There were some key findings of differences in teachers' perceptions between subsamples categorized by teaching experience, education background, and teaching subjects. Firstly, novice teachers have more positive views of STEM education; perhaps, they are more exposed to informal learning about STEM education, such as self-learning on the Internet and joining some STEM workshops. Secondly, the results indicated that the higher the education background, the more proper view of STEM education and the more difficulty felt in STEM implementation. Likewise, a similar phenomenon aforementioned occurred with science teachers. These results are rational when Vietnamese teachers approached STEM toward a discipline orientation. Novice teachers and science teachers are advocated as a potential resource to succeed in STEM education in Vietnam. Curricular and pedagogical collaboration is a promising way to sustain STEM education [25].

Author Contributions: Data curation, N.T.T.K. and N.V.B.; Formal analysis, N.T.T.K.; Funding acquisition, C.-Y.C.; Investigation, N.T.T.K.; Methodology, P.-L.L., N.V.B., J.L. and C.-Y.C.; Project administration, C.-Y.C.; Resources, C.-Y.C.; Supervision, C.-Y.C.; Validation, N.T.T.K.; Writing-original draft, N.T.T.K. All authors have read and agreed to the published version of the manuscript.

Funding: This research is supported in part by the Ministry of Science and Technology (MOST), Taiwan, R.O.C., under the grant number MOST 106-2511-S-003-050-MY3, "STEM for 2TV (Science, Technology, Engineering, and Mathematics for Taiwan, Thailand, and Vietnam): A Joint Adventure in Science Education Research and Practice; the "Institute for Research Excellence in Learning Sciences" of National Taiwan Normal University (NTNU) from The Featured Areas Research Center Program within the framework of the Higher Education Sprout Project by the Ministry of Education (MOE) in Taiwan; and National Taiwan Normal University Subsidy for Talent Promotion Program.

Acknowledgments: The authors would like to express their gratefulness to Terrence from the Science Education Center, NTNU, who helped in the English editing process.

Conflicts of Interest: The authors declare no conflict of interest. The founding sponsors had no role in the design of the study; in the collection, analyses, or interpretation of data; in the writing of the manuscript, and in the decision to publish the results.

\section{References}

1. OECD. PISA 2015 Results (Volume I): Excellence and Equity in Education; OECD Publishing: Paris, France, 2016; Volume I.

2. Chiu, M.H.; Duit, R. Globalization: Science education from an international perspective. J. Res. Sci. Teach. 2011, 48, 553-566. [CrossRef]

3. OECD. Education at a Glance 2017: OECD Indicators; OECD Publishing: Paris, France, 2017.

4. Uvalic-Trumbic, S.; Daniel, J. Sustainable Development Begins with Education. J. Learn. Dev. 2016, 3, 3-8.

5. Mathis, C.A.; Siverling, E.A.; Moore, T.J.; Douglas, K.A.; Guzey, S.S. Supporting engineering design ideas with science and mathematics: A case study of middle school life science students. Int. J. Educ. Math. Sci. Technol. 2018, 6, 424-442. [CrossRef]

6. Guzey, S.S.; Moore, T.J.; Harwell, M.; Moreno, M. STEM Integration in Middle School Life Science: Student Learning and Attitudes. J. Sci. Educ. Technol. 2016, 25, 550-560. [CrossRef]

7. Moore, T.J.; Miller, R.L.; Lesh, R.A.; Stohlmann, M.S.; Kim, Y.R. Modeling in Engineering: The Role of Representational Fluency in Students' Conceptual Understanding. J. Eng. Educ. 2013, 102, 141-178. [CrossRef]

8. Bybee, R.W. What is STEM education? Science 2010, 329, 996. [CrossRef]

9. Sanders, M. STEM, STEM education, STEMmania. Technol. Teach. 2009, 68, 20-26. 
10. Honey, M.A.; Pearson, G.; Schweingruber, H. STEM Integration in K-12 Education: Status, Prospects, and an Agenda for Research; The National Academics Press: Washington, DC, USA, 2014.

11. Peterman, K.; Kermish-Allen, R.; Knezek, G.; Christensen, R.; Tyler-Wood, T. Measuring Student Career Interest within the Context of Technology-Enhanced STEM Projects: A Cross-Project Comparison Study Based on the Career Interest Questionnaire. J. Sci. Educ. Technol. 2016, 25, 833-845. [CrossRef]

12. Stevens, S.; Andrade, R.; Page, M. Motivating Young Native American Students to Pursue STEM Learning Through a Culturally Relevant Science Program. J. Sci. Educ. Technol. 2016, 25, 947-960. [CrossRef]

13. Vennix, J.; den Brok, P.; Taconis, R. Do outreach activities in secondary STEM education motivate students and improve their attitudes towards STEM? Int. J. Sci. Educ. 2018, 40, 1263-1283. [CrossRef]

14. Bien, N.V.; Hai, T.D.; Duc, T.M.; Hanh, N.V.; Tho, C.C.; Thuan, N.V.; Thuoc, D.V.; Trinh, T.B. STEM Education in Secondary Schools; Vietnam Education Publishing House Limited Company: Hanoi, Vietnam, 2019.

15. Wang, H.; Moore, T.J.; Roehrig, G.H.; Park, M.S. STEM Integration: Teacher Perceptions and Practice STEM Integration: Teacher Perceptions and Practice. J. Pre-Coll. Eng. Educ. Res. 2011, 1, 1-13.

16. Park, H.; Byun, S.Y.; Sim, J.; Han, H.; Baek, Y.S. Teachers' perceptions and practices of STEAM education in South Korea. Eurasia J. Math. Sci. Technol. Educ. 2016, 12, 1739-1753.

17. Thibaut, L.; Knipprath, H.; Dehaene, W.; Depaepe, F. How school context and personal factors relate to teachers' attitudes toward teaching integrated STEM. Int. J. Technol. Des. Educ. 2018, 28, 631-651. [CrossRef]

18. Margot, K.C.; Kettler, T. Teachers' perception of STEM integration and education: A systematic literature review. Int. J. STEM Educ. 2019, 6, 1-16. [CrossRef]

19. Yildirim, B. An Analyses and Meta-Synthesis of Research on STEM Education. J. Educ. Pract. 2016, 7, $23-33$.

20. Chesky, N.Z.; Wolfmeyer, M.R. Philosophy of STEM Education: A Critical Investigation; Palgrave Macmillan: New York, NY, USA, 2015.

21. Wachira, S.; Deborah, L. Perceptions of in-service teachers toward teaching STEM in Thailand. Asia Pac. Forum Sci. Learn. Teach. 2017, 18, 1-23.

22. Bonnett, M. Education for sustainable development: A coherent philosophy for environmental education? Camb. J. Educ. 1999, 29, 313-324. [CrossRef]

23. Lélé, S.M. Sustainable development: A critical review. World Dev. 1991, 19, 607-621. [CrossRef]

24. World Commission on Environment and Development (WCED). Our Common Future; University Press: Oxford, UK, 1987.

25. Feinstein, N.W.; Kirchgasler, K.L. Sustainability in Science Education? How the Next Generation Science Standards Approach Sustainability, and Why It Matters. Sci. Educ. 2015, 99, 121-144. [CrossRef]

26. Jerneck, A.; Olsson, L.; Ness, B.; Anderberg, S.; Baier, M.; Clark, E.; Hickler, T.; Hornborg, A.; Kronsell, A.; Lovbrand, E.; et al. Structuring sustainability science. Sustain. Sci. 2011, 6, 69-82. [CrossRef]

27. Altan, E.B.; Ozturk, N.; Turkoglu, A.Y. Socio-Scientific Issues as a Context for STEM Education: A Case Study Research with Pre-Service Science Teachers. Eur. J. Educ. Res. 2018, 7, 805-812.

28. Radloff, S.G.J. Investigating Preservice STEM Teacher Conceptions of STEM Education. J. Sci. Educ. Technol. 2016, 25, 759-774. [CrossRef]

29. Selcen Guzey, S.; Harwell, M.; Moreno, M.; Peralta, Y.; Moore, T.J. The Impact of Design-Based STEM Integration Curricula on Student Achievement in Engineering, Science, and Mathematics. J. Sci. Educ. Technol. 2017, 26, 207-222. [CrossRef]

30. Bybee, R.W. Advancing STEM Education: A 2020 Vision. Technol. Eng. Teach. 2010, 70, 30-35.

31. Quigley, C.F.; Herro, D. 'Finding the Joy in the Unknown': Implementation of STEAM Teaching Practices in Middle School Science and Math Classrooms. J. Sci. Educ. Technol. 2016, 25, 410-426. [CrossRef]

32. UNESCO. Global Education Monitoring Report: Education for People and Planet-Creating Sustainable Futures For All; UNESCO: Paris, France, 2016.

33. UNESCO. Global Education Monitoring Report: Accountability in education-Meeting our Commitments; UNESCO: Paris, France, 2017.

34. UNESCO. Global Education Monitoring Report: Migration, Displacement and Education-Building Bridges, Not Walls; UNESCO: Paris, France, 2018.

35. Wahono, B.; Chang, C.Y. Assessing Teacher's Attitude, Knowledge, and Application (AKA) on STEM: An Effort to Foster the Sustainable Development of STEM Educsation. Sustainability 2019, 11, 950. [CrossRef]

36. Ministry of Education and Training (Vietnam). Viet Nam: Second Secondary Education Sector Development Program; MOET: Hanoi, Vietnam, 2016. 
37. Dijksterhuis, A.; Van Knippenberg, A. The relation between perception and behavior, or how to win a game of trivial pursuit. J. Pers. Soc. Psychol. 1998, 74, 865-877. [CrossRef]

38. Prinz, W. A Common Coding Approach to Perception and Action. In Relationships Between Perception and Action; Neumann, O., Prinz, W., Eds.; Springer: Berlin/Heidelberg, Germany, 1990; pp. 167-201.

39. Al Salami, M.K.; Makela, C.J.; de Miranda, M.A. Assessing changes in teachers' attitudes toward interdisciplinary STEM teaching. Int. J. Technol. Des. Educ. 2017, 27, 63-88. [CrossRef]

40. Cavlazoglu, B.; Stuessy, C. Changes in science teachers' conceptions and connections of STEM concepts and earthquake engineering. J. Educ. Res. 2017, 110, 239-254. [CrossRef]

41. Nadelson, L.S.; Seifert, A.L. Integrated STEM defined: Contexts, challenges, and the future. J. Educ. Res. 2017, 110, 221-223. [CrossRef]

42. Pryor, B.W.; Pryor, C.R.; Kang, R. Teachers' thoughts on integrating STEM into social studies instruction: Beliefs, attitudes, and behavioral decisions. J. Soc. Stud. Res. 2016, 40, 123-136. [CrossRef]

43. Thibaut, L.; Knipprath, H.; Dehaene, W.; Depaepe, F. The influence of teachers' attitudes and school context on instructional practices in integrated STEM education. Teach. Teach. Educ. 2018, 71, 190-205. [CrossRef]

44. Bandura, A. Self-Efficacy: The Exercise of Control; Freeman: New York, NY, USA, 1977.

45. Bandura, A. Social Foundations of Thought and Action: A Social Cognitive Theory; Prentice-Hall: Englewood Cliffs, NJ, USA, 1986.

46. Bandura, A. Self-efficacy. In Encyclopedia of Human Behavior; Ramachaudran, I.V.S., Ed.; Academic Press: New York, NY, USA, 1994; pp. 71-81.

47. Hoy, A.W.; Spero, R.B. Changes in teacher efficacy during the early years of teaching: A comparison of four measures. Teach. Teach. Educ. 2005, 21, 343-356. [CrossRef]

48. Jarski, R.W.; Kulig, K.; Olson, R.E. Clinical teaching in physical therapy: Student and teacher perceptions. Phys. Ther. 1990, 70, 173-178. [CrossRef]

49. Warren, S.C.; Plerson, F.M. Comparison of Characteristics and Attitudes of Entry-Level Bachelor 's and Master' s Degree Students in Physical Therapy. Phys. Ther. 1994, 74, 333-348. [CrossRef]

50. Thibaut, L.; Knipprath, H.; Dehaene, W.; Depaepe, F. Teachers' Attitudes Toward Teaching Integrated STEM: The Impact of Personal Background Characteristics and School Context. Int. J. Sci. Math. Educ. 2018, 1-21. [CrossRef]

51. Cohen, K.; Manion, L. Research Methods in Education, 7th ed.; Routledge: London, UK, 2011.

52. Cohen, J.W. Statistical Power Analysis for the Behavioral Sciences, 2nd ed.; Lawrence Erlbaum Associates: Hillsdale, NJ, USA, 1988.

53. Shulman, L. Knowledge and Teaching: Foundations of the New Reform. Harv. Educ. Rev. 1987, 57, 1-23. [CrossRef]

54. Roebuck, K.I.; Warden, M.A. Searching for the Center on the Mathematics-Science Continuum. Sch. Sci. Math. 1998, 98, 328-333. [CrossRef]

55. Stodolsky, S.S.; Grossman, P.L. The Impact of Subject Matter on Curricular Activity: An Analysis of Five Academic Subjects. Am. Educ. Res. J. 1995, 32, 227-249. [CrossRef]

56. Guzey, S.S.; Ring-Whalen, E.A.; Harwell, M.; Peralta, Y. Life STEM: A Case Study of Life Science Learning Through Engineering Design. Int. J. Sci. Math. Educ. 2017, 17, 23-42. [CrossRef]

57. Bell, D.; Morrison-Love, D.; Wooff, D.; McLain, M. STEM education in the twenty-first century: Learning at work-an exploration of design and technology teacher perceptions and practices. Int. J. Technol. Des. Educ. 2017, 28, 721-737. [CrossRef]

58. Moore, T.J.; Smith, K.A. Advancing the State of the Art of STEM Integration. J. STEM Educ. 2014, 15, 5-10.

59. Kelley, T.R.; Knowles, J.G. A conceptual framework for integrated STEM education. Int. J. STEM Educ. 2016, 3, 1-11. [CrossRef]

60. Jannah, U.R.; Nusantara, T.; Yulianto, F.E. Restructuring of Stem-Based Student Thinking in Constructing the Concept of Definition a Function. Int. J. Civ. Eng. Technol. 2019, 10, 795-806.

61. El-Deghaidy, H.; Mansour, N.; Alzaghibi, M.; Alhammad, K. Context of STEM integration in schools: Views from in-service science teachers. Eurasia J. Math. Sci. Technol. Educ. 2017, 13, 2459-2484. [CrossRef]

62. Ghaith, G.; Yaghi, H. Relationships among experience, teacher efficacy, and attitudes toward the implementation of instructional innovation. Teach. Teach. Educ. 1997, 13, 451-458. [CrossRef] 
63. Weinstein, C.S. Preservice teachers' expectations about the first year of teaching. Teach. Teach. Educ. 1988, 4, 31-40. [CrossRef]

64. Cotterill-Walker, S.M. Where is the evidence that master's level nursing education makes a difference to patient care? A literature review. Nurse Educ. Today 2012, 32, 57-64. [CrossRef] 